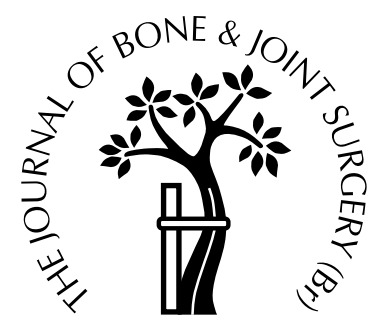

\title{
The PROSTALAC functional spacer in two-stage revision for infected knee replacements
}

\author{
Fares S. Haddad, Bassam A. Masri, David Campbell, \\ Robert W. McGraw, Christopher P. Beauchamp, Clive P. Duncan \\ From the University of British Columbia, Vancouver, Canada
}

$\mathbf{T}$ he PROSTALAC functional spacer is made of antibiotic-loaded acrylic cement but has a small metal-on-polythene articular surface. We have used it as an interim spacer in two-stage exchange arthroplasty for infected total knee replacement. PROSTALAC allows continuous rehabilitation between stages as it maintains good alignment and stability of the knee and a reasonable range of movement. It also helps to maintain the soft-tissue planes, which facilitates the second-stage procedure.

We reviewed 45 consecutive patients, treated over a period of nine years. The mean follow-up was for 48 months (20 to 112). At final review, there was no evidence of infection in 41 patients $(91 \%)$; only one had a recurrent infection with the same organism. There was improvement in the Hospital for Special Surgery knee score between stages and at final review. The range of movement was maintained between stages. Complications were primarily related to the extensor mechanism and stability of the knee between stages. Both of these problems decreased with refinement of the design of the implant.

The rate of cure of the infection in our patients was similar to that using other methods. Movement of the knee does not appear to hinder control of infection.

J Bone Joint Surg [Br] 2000;82-B:807-12.

Received 18 August 1999; Accepted after revision 10 December 1999

F. S. Haddad, BSc, MCh Orth, FRCS Orth, Clinical Research Fellow

B. A. Masri, MD, FRCS C, Clinical Associate Professor

D. Campbell, MD, Former Fellow

R. W. McGraw, MD, FRCS C, Professor

C. P. Duncan, MD, FRCS C, Professor and Chairman

Department of Orthopaedics, University of British Columbia, Vancouver, British Columbia, Canada.

C. P. Beauchamp, MD, FRCS C, Assistant Professor

Mayo Clinic, Scottsdale, Arizona, USA.

Correspondence should be sent to Dr B. A. Masri at the Division of Reconstructive Orthopaedics, Third Floor, Laurel Pavilion, 910 West Tenth Avenue, Vancouver, British Columbia, Canada V5Z 4E3.

(C2000 British Editorial Society of Bone and Joint Surgery 0301-620X/00/610486 \$2.00

VOL. 82-B, No. 6, AUGUST 2000
Despite excellent long-term results after total knee replacement (TKR), ${ }^{1-3}$ and rigorous antibiotic prophylaxis, between $1.0 \%$ and $2.0 \%$ of TKRs are complicated by infection $^{4-7}$ with associated morbidity and increased cost. $^{8-10}$ There are a number of options for the treatment of an infected arthroplasty. ${ }^{11-25}$ Re-implantation of a new prosthesis after removal of the infected implant and thorough debridement, if technically feasible, is the most acceptable. While there have been some reports of successful immediate re-implantation, ${ }^{18,25-27}$ the best results were obtained when this was delayed by at least six weeks (twostage exchange) with rates of control of infection over $90 \%$. $^{10,15,16,18,27-29}$

The major disadvantage in two-stage exchange arthroplasty is that the interval between stages is often associated with impaired mobility, limited stability, and pain. Reimplantation is often difficult because of arthrofibrosis. In about $20 \%$ of patients a less than optimal result was directly or indirectly attributable to the delay between the two stages. ${ }^{17,30,31}$ Several techniques have been described to help to preserve the length of the limb and to minimise soft-tissue contractures. These include the use of nonarticulating antibiotic-loaded cement spacers between stages. ${ }^{15,18,19,21,32}$ In addition to their ability to elute high levels of antibiotics, these spacers, in contrast to antibioticloaded cement beads, decrease the scarring within the joint and facilitate re-implantation. The operation, however, is still difficult and scarring is substantial, particularly in the lateral and medial gutters, and posteriorly. These spacer blocks are often unstable and may cause bone erosion. ${ }^{33}$

To refine further the role of spacers between stages, we introduced the concept of articulated spacers in the late 1980 s with the prosthesis of antibiotic-loaded acrylic cement (PROSTALAC), initially developed for the hip, ${ }^{34,35}$ and subsequently for the knee. ${ }^{36}$ We have assessed the effect of the PROSTALAC knee spacer on the function of the knee between stages and after re-implantation, and on the eradication of infection.

\section{Patients and Methods}

The PROSTALAC knee prosthesis has femoral (Figs 1a and 1b) and tibial (Fig. 1c) components which are made primarily of antibiotic-loaded Palacos bone cement (Smith 


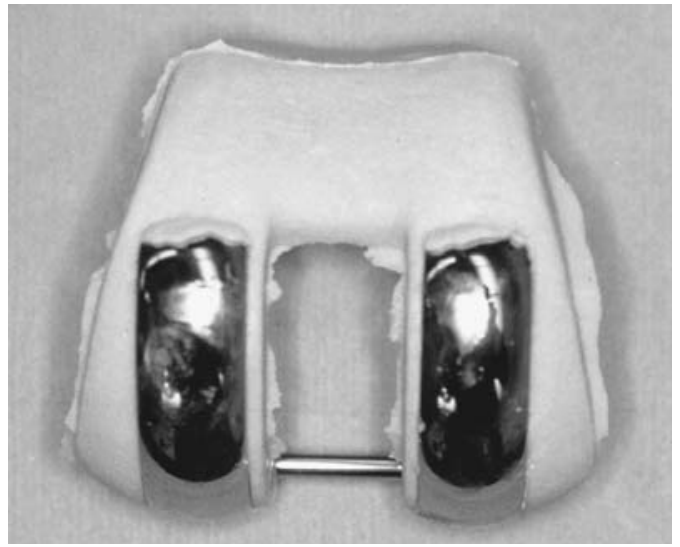

Fig. 1a

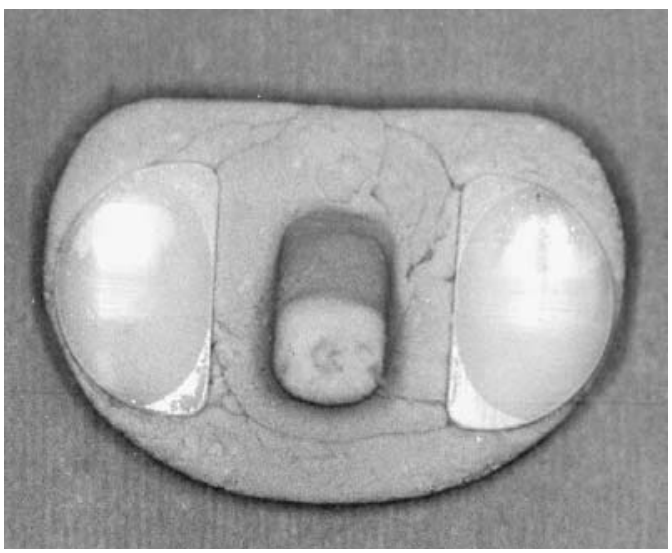

Fig. 1c

and Nephew Richards, Memphis, Tennessee), with a small metal-on-polyethylene articular surface. Various sizes and thicknesses are available. Using a series of moulds each prosthesis is made in the operating theatre before insertion. This system was first used in 1987, and has evolved from a handmade facsimile of a knee prosthesis to the sophisticated posterior-stabilised design which is currently in use.

After removal of the infected prosthesis and thorough debridement of all infected and necrotic tissue, the femur and tibia were prepared in a manner similar to that for revision of TKR without removing excessive amounts of bone. Trial implants were inserted using standard instruments for revision. Deficiencies of distal femoral bone were augmented by increasing the thickness of the PROSTALAC femoral component. Moulds which produce three different distal thicknesses were available for each size of PROSTALAC to allow accurate placement of the joint line. Posterior and isolated medial or lateral distal deficiencies were made-up with bone cement when the implant was inserted. On the tibial side, any deficiencies were also augmented with bone cement. Each tibial size allowed a thickness of implant from 12 to $34 \mathrm{~mm}$. Once the cement had cured, the implants were removed from the moulds, and cemented to the host bone, at a late stage of polymerisation if necessary, to allow fixation without undue inter-

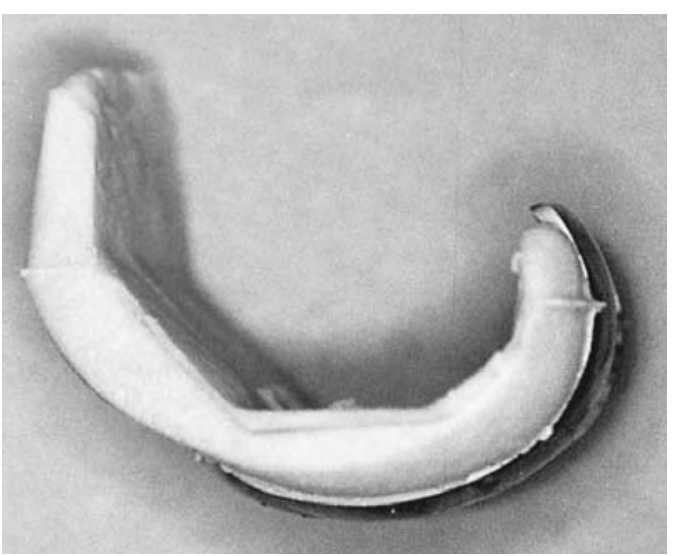

Fig. 1b

The current PROSTALAC system consists of a femoral component ( $\mathrm{a}$ and $\mathrm{b}$ ) and a tibial component (c) which articulate in a posterior stabilised fashion to form a facsimile of a knee replacement. Although most of this implant is made of antibiotic-loaded bone cement, the articular surface is a low-friction articulation of stainless-steel on ultrahigh-molecular-weight polyethylene. On the femoral side, a cross-bar connects to two halves of the articular surface, and acts as the cam mechanism in the posterior stabilised design. On the tibial side, there is a spine made of antibiotic-loaded cement. This articulates with the cam as in any other posterior-stabilised design.

digitation of the cement into bone. In cases in which the bone stock was good, simple press-fit fixation sufficed. The patella was not resurfaced. The patient was then treated at home and given a six-week course of intravenous antibiotics. Four weeks later, an aspiration biopsy was taken to confirm the eradication of infection. After a further two weeks, the second-stage re-implantation was carried out with antibiotic-loaded cement.

Between 1 April 1987 and 31 March 1996, 59 patients with infected knee arthroplasty were admitted to hospital. Of these, 45 were fully reviewed and included in this series. Of the 14 patients excluded from the study (Table I), 11 were treated by means other than two-stage exchange arthroplasty using the PROSTALAC system since they were deemed not to be suitable for such treatment. One other patient was too ill for a second-stage procedure. Two patients died and had no evidence of recurrent infection at the time of death. No patient was lost to follow-up. A patient who died 20 months after operation and was still infected was included. There were 26 women and 19 men with a mean follow-up of 48 months (20 to 112). Their mean age was 69 years (26 to 83). The reason for primary replacement was osteoarthritis in 33, rheumatoid arthritis in six, osteonecrosis in one, post-traumatic arthritis in three, haemophilic arthropathy in one, and neuropathic arthro- 
Table I. The reasons for exclusion of 14 patients from the study

\begin{tabular}{ll}
\hline Reason for exclusion & Number \\
\hline Above-knee amputation & 2 \\
Arthrodesis & 2 \\
Non-functional spacer & 4 \\
Incision and drainage & 2 \\
Second stage never undertaken & 1 \\
Excision arthroplasty & 1 \\
Patient died before two-year follow-up & 2 \\
\hline
\end{tabular}

pathy in one. A total of 20 patients had an infected primary TKR, 16 had an infected first revision, eight an infected second or third revision, and one a failed two-stage exchange. Drainage or debridement had been undertaken elsewhere in 26 and 16 had discharging sinuses. The infecting organisms were identified in 40 cases and are shown in Table II. Despite clinically obvious infection five patients had negative cultures.

All patients had a two-stage exchange arthroplasty using the PROSTALAC system. Earlier versions were used in 22 patients with either a handmade facsimile of a knee replacement, a cement-on-cement moulded prosthesis or a non-posterior stabilised low-friction moulded prosthesis; 23 received the current version of the PROSTALAC. The mean interval between stages for the entire cohort was 15.5 weeks (3.6 to 96.7). The antibiotics used in the cement depended on the sensitivity profile of the infecting organism. In 37 patients, a combination of tobramycin (1.2 to $3.6 \mathrm{~g}$ ) and vancomycin ( 0.5 to $1.5 \mathrm{~g}$ ) was used, in one tobramycin alone, and in four vancomycin was used alone. A combination of tobramycin, vancomycin and penicillin $\mathrm{G}$ was used in one patient and tobramycin and penicillin $G$ in two. All patients received parenteral antibiotic therapy between stages. At the second stage, all procedures were carried out using antibiotic-loaded cement with $1.2 \mathrm{~g}$ of tobramycin per package. A condylar-type revision implant was used in all patients with the exception of two, in whom a rotating hinge implant was required.
Results

Control of infection. Four patients had recurrence of infection (Table III). Three presented with infections caused by a different organism. One was treated by above-knee amputation and two with suppressive antibiotics. One died from unrelated causes at 20 months. Initially we did not measure serial ESR and levels of C-reactive protein, although these are now routine. Any patient who had a suboptimal result was investigated by aspiration to exclude infection. The overall control of infection was $91 \%$.

Relief of pain. The main advantage of this approach, compared with a standard excision arthroplasty was the relief of pain observed between stages. In the early cases, particularly in those in which a low friction-bearing surface was not used, there was mild to moderate residual pain in five of ten knees, associated with a grating sensation and crepitus on knee movement. Only one of the patients who received a modified implant complained of persistent pain in relation to severe ectopic ossification in the anteromedial soft tissues.

Functional outcome. Function was assessed by extensor lag, flexion deformity, range of flexion and the Hospital for Special Surgery (HSS) knee score (Table IV). The HSS knee score was used as an indicator of the change between stages as well as between the initial presentation and final reconstruction. The mean HSS knee score was 42.4 on presentation; it improved to a mean of 55.9 after the first stage and to a mean of 71.4 at final review. These improvements were significant (Student $t$-test, $\mathrm{p}<0.0005$ ). One of the aims of this method of treatment of infection was to maintain mobility between stages, thus simplifying the revision procedure. The range of movement seen in the interval period confirmed this. The small residual extensor lag at final review supports the efficacy of the PROSTALAC in allowing early rehabilitation.

Complications. As complications were more often seen with the earlier designs, we divided our cohort into two groups (Table V). Group I was treated with the earlier

Table II. Organisms found in 40 infected knees

\begin{tabular}{lc}
\hline & Number \\
\hline Single organisms & 18 \\
Staphylococcus epidermidis & 9 \\
Staphylococcus aureus & 1 \\
Coagulase-negative staphylococcus not Staph. epidermidis & 1 \\
Escherichia coli & 1 \\
Peptostreptococcus species & 1 \\
Streptococcus species & 1 \\
Mixed infections & 1 \\
Actinomyces and Mycobacteria & 1 \\
Coliforms and Staphylococcus epidermidis & 1 \\
Enterococcus and Staphylococcus epidermidis & 1 \\
Enterococcus, Staphylococcus haemolyticus and diphtheroids & 1 \\
Staphylococcus epidermidis and coagulase-negative staphylococcus not Staph. epidermidis & 1 \\
Staphylococcus epidermidis and Mycobacterium & 1 \\
Staphylococcus epidermidis, Enterococcus, and Serratia & 1 \\
Staphylococcus epidermidis and Peptostreptococcus & 1 \\
Staphylococcus epidermidis and Bacillus species & 1 \\
\hline
\end{tabular}

VOL. 82-B, No. 6, AUGUST 2000 
Table III. The organisms identified in the four patients with recurrent infections

\begin{tabular}{llll}
\hline Original organism & Recurrent organism & Treatment & Comments \\
\hline Staphylococcus epidermidis & Same & Antibiotics & Previous failed two-stage exchange \\
Staphylococcus epidermidis & Streptococcus agalactiae & Antibiotics & Chronic sinus \\
Staphylococcus epidermidis & Staphylococcus aureus & Amputation & \\
Staphylococcus epidermidis & Enterococcus and Staphylococcus epidermidis & Antibiotics & Died 20 months postoperatively from unrelated causes
\end{tabular}

Table IV. The HSS knee score and functional parameters, before and after surgery, and at the final follow-up

\begin{tabular}{lccc}
\hline & Preop & Postop & Final follow-up \\
\hline Mean HSS score & $42.4(11$ to 74$)$ & $55.9(18$ to 87$)$ & $71.5(32$ to 96$)$ \\
flexion deformity in degrees (range) & $8.8(-5$ to 30$)$ & $7.8(-5$ to 40$)$ & $4.1(0$ to 30$)$ \\
flexion in degrees (range) & $71.2(10$ to 130$)$ & 76.1 (20 to 115$)$ & $94.5(20$ to 135$)$ \\
extensor lag in degrees (range) & $7.9(0$ to 50$)$ & 9.8 (0 to 90$)$ & $2.8(0$ to 30$)$ \\
\hline
\end{tabular}

Table V. Complications which occurred after PROSTALAC knee arthroplasty in group-I patients who received the original PROSTALAC system and group-II patients who received the current system

\begin{tabular}{|c|c|c|c|}
\hline \multicolumn{2}{|l|}{ Group I } & \multicolumn{2}{|l|}{ Group II } \\
\hline Complication & $\begin{array}{l}\text { Number of } \\
\text { patients }\end{array}$ & Complication & $\begin{array}{l}\text { Number of } \\
\text { patients }\end{array}$ \\
\hline Patellar instability after second stage & 3 & Dislocated patella between stages & 2 \\
\hline Ruptured patellar tendon & 1 & Late fracture of patella & 1 \\
\hline Posterior dislocation of knee between stages & 3 & $\begin{array}{l}\text { Dislocated knee between stages and ruptured patellar } \\
\text { tendon }\end{array}$ & 1 \\
\hline Instability between stages requiring immobilisation in cast & 4 & Severe patellofemoral pain & 1 \\
\hline Instability after second stage & 1 & Collateral ligament instability between stages & 1 \\
\hline $\begin{array}{l}\text { Dissociation of the hinge mechanism in a } \\
\text { rotating hinge implant requiring revision }\end{array}$ & 1 & Wound breakdown between stages & 1 \\
\hline Unstable proximal tibiofibular joint & 1 & Undisplaced fracture of distal femur & 1 \\
\hline Pulmonary embolism & 1 & & \\
\hline
\end{tabular}

generations of the PROSTALAC and group II included those managed with the current low-friction posterior-stabilised design.

A substantial number of complications were related to the extensor mechanism. Three group-I patients continued to have problems with patellar instability after the second stage. In group II, two had patellar dislocations between stages which were corrected at the second stage. Rupture of the patellar tendon occurred in one patient in each group with a poor outcome. Marked patellofemoral pain was seen in two patients in group II in whom there was no evidence of recurrent infection.

Because of the minimal constraint in the PROSTALAC components in group I, three patients had posterior dislocation of the tibia, requiring closed reduction and immobilisation in a cast. This was seen in only one patient in group II, after rupture of the patellar tendon. In addition to anteroposterior and patellofemoral instability, collateral ligament instability was seen between stages in four patients in group I, and in one in group II. They required bracing between stages. Instability after the second stage was seen in one patient in group I and none in group II. The instability was asymptomatic since the patient had a neuropathic arthropathy.
Severe breakdown of the wound between stages requiring a medial gastrocnemius flap, occurred in one patient in group II. She ultimately needed a free transfer of latissimus dorsi. After the soft tissues healed, she had a re-implantation two years after the first stage. At final review, there was no evidence of ongoing infection, but she was not satisfied with the function of her knee. Her HSS knee score was 34 , with a final range of flexion from $0^{\circ}$ to $20^{\circ}$. She might have been better served by an arthrodesis.

\section{Discussion}

The best results of treatment of an infected TKR have been reported by Windsor et $\mathrm{al}^{37}$ in which no spacer was used between stages. There was recurrence of the original infection in one of 38 knees $(2.6 \%)$ and a new infection in another three of 38 knees $(7.9 \%)$. These are similar to our figures of $2.2 \%$ (1 of 45) and 6.7\% (3 of 45), respectively. Although PROSTALAC components include small amounts of polyethylene and metal, they do not seem to compromise the rate of control of infection since our results were similar to the best previously reported. There is no evidence to suggest that the use of antibiotic-loaded cement spacers between stages enhances the rate of eradication of 
infection, but this technique has been widely adopted, primarily to maintain a joint space and to improve the ease of re-implantation. Several other articulated spacers have been described ${ }^{38-41}$ since the first description of PROSTALAC. ${ }^{36}$ The advantages include continued mobility, ease of rehabilitation and ease of re-implantation. Our results showed clearly the improved function between stages and we believe that a mobile knee allows easier second-stage operation and facilitates rehabilitation. A higher dose of antibiotic can be added to the bone cement in a spacer than in a one-stage exchange or a definitive re-implantation, in which the dose must be limited because of the risk of weakening the cement. ${ }^{42,43}$ However, the prosthesis used as a spacer is expensive and is discarded after six weeks.

Most of the complications in this series were related to the extensor mechanism. A thin patella which is difficult to resurface has an increased risk of subluxation. This, fortunately, was rarely symptomatic in low-demand patients. In those who are more active severe pain may persist and a patellectomy may become necessary. Rupture of the patellar tendon is a devastating complication. The preoperative range of movement in our patients (Table IV) confirmed that infected knee replacements were 'stiff' putting great strain on the insertion of the patellar tendon unless the latter was protected. An extensile exposure is required for safe surgery.

In a comparison of the cost of treatment of 20 consecutive infected TKRs with 30 primary TKRs and 30 aseptic revision knee arthroplasties during the same period it was found that surgical treatment of an infected total knee prosthesis was twice as expensive as that of an aseptic revision and three to four times that of a primary TKR. ${ }^{44}$ Much of that cost was due to the expense of prolonged hospitalisation. Any method of treatment which allows earlier discharge from hospital is desirable and should have economic advantages. Although we did not have a control group for comparison, our impression was that the PROSTALAC functional spacer allowed earlier mobilisation free from pain and should therefore lead to a shorter stay in hospital. The savings in terms of the latter greatly outweigh the increased cost of the PROSTALAC components.

One of the authors (FSH) was supported by the John Charnley and BOA/ Wishbone Trusts and by the Norman Capener Travelling Fellowship.

Although none of the authors have received or will receive benefits for personal or professional use from a commercial party related directly or indirectly to the subject of this article, benefits have been or will be received but are directed solely to a research fund, foundation, educational institution, or other non-profit institution with which one or more of the authors is associated.

\section{References}

1. Diduch DR, Insall IN, Scott WN, Scuderi GR, Font-Rodriguez D. Total knee replacement in young, active patients: long-term followup and functional outcome. J Bone Joint Surg [Am] 1997;79-A:57582.

2. Ranawat CS, Flynn WF, Saddler S, Hansraj KK, Maynard MJ. Long term results of the total condylar knee arthroplasty: a 15-year survivorship study. Clin Orthop 1993;286:94-102.
3. Robertsson O, Knutson K, Lewold S, Goodman S, Lidgren L. Knee arthroplasty in rheumatoid arthritis: a report from the Swedish Knee Arthroplasty Register on 4381 primary operations 1985-1995. Acta Orthop Scand 1997;68:545-53.

4. Bengtson K, Knutson K, Lidgren $\mathbf{L}$. Revision of infected knee arthroplasty. Acta Orthop Scand 1986;57:489-94.

5. Bengtson S, Knutson $\mathbf{K}$. The infected knee arthroplasty: a 6-year follow-up of 357 cases. Acta Orthop Scand 1991;62:301-11.

6. Gill GS, Mills DM. Long-term follow-up evaluation of 1000 consecutive cemented total knee arthroplasties. Clin Orthop 1991;273:66-76.

7. Rand JA, Fitzgerald RH Jr. Diagnosis and management of the infected total knee arthroplasty. Orthop Clin North Am 1989;20:201-10.

8. Barrack RL. Economics of the infected total knee replacement. Orthopedics 1996;19:780-2.

9. Sculco TP. The economic impact of infected total joint arthroplasty. AAOS Instructional Course Lectures 1993;42:349-51.

10. Woods GW, Lionberger DR, Tullos HS. Failed total knee arthroplasty: revision and arthrodesis for infectious and noninfectious complications. Clin Orthop 1983;173:184-90.

11. Hanssen AD, Rand JA, Osmon DR. Treatment of the infected total knee arthroplasty with insertion of another prosthesis: the effect of antibiotic-impregnated bone cement. Clin Orthop 1994;309:44-55.

12. Rand JA, Bryan BS. Reimplantation for the salvage of an infected total knee arthroplasty. J Bone Joint Surg [Am] 1983;65-A:1081-6.

13. Rand JA, Bryan RS, Morrey BF, Westholm F. Management of infected total knee arthroplasty. Clin Orthop 1986;205:75-85.

14. Rand JA. Alternatives to reimplantation for salvage of the total knee arthroplasty complicated by infection. J Bone Joint Surg [Am] 1993;75-A:282-9.

15. Wilde AH, Ruth JT. Two-stage reimplantation in infected total knee arthroplasty. Clin Orthop 1988;236:23-35.

16. Wilde AH. Management of infected knee and hip prostheses. Curr Opin Rheumatol 1994;6:172-6.

17. Insall JN, Thompson FM, Brause BD. Two-stage reimplantation for the salvage of infected total knee arthroplasty. J Bone Joint Surg [Am] 1983;65-A:1087-98.

18. Borden LS, Gearen PF. Infected total knee arthroplasty: a protocol for management. J Arthroplasty 1987;2:27-36.

19. Meislin R, Zuckerman JD. Management of an infected total knee arthroplasty. Bull Hosp Jt Dis Orthop Inst 1989;49:21-36.

20. Mont MA, Waldman B, Banerjee C, Pacheco IH, Hungerford DS. Multiple irrigation, debridement and retention of components in infected total knee arthroplasty. J Arthroplasty 1997;12:426-33.

21. Moffey BF, Westholm F, Schoifet S, Rand JA, Bryan RS. Longterm results of various treatment options for infected total knee arthroplasty. Clin Orthop 1989;248:120-8.

22. Simonian PT, Brause BD, Wickiewicz TL. Candida infection after total knee arthroplasty: management without resection or amphotericin B. J Arthroplasty 1997;12:825-9.

23. Bliss DG, McBride GG. Infected total knee arthroplasties. Clin Orthop 1985;199:207-14.

24. Ellingsen DE, Rand JA. Intramedullary arthrodesis of the knee after failed total knee arthroplasty. J Bone Joint Surg [Am] 1994;76-A:870-7.

25. Freeman MAR, Sudlow RA, Casewell MW, Radcliff SS. The management of infected total knee replacements. J Bone Joint Surg [Br] 1985;67-B:764-8.

26. Göksan SB, Freeman MAR. One-stage reimplantation for infected total knee arthroplasty. J Bone Joint Surg [Br] 1992;74-B:78-82.

27. Teeny SM, Dorr L, Murata G, Conaty P. Treatment of infected total knee arthroplasty: irrigation and debridement versus two-stage reimplantation. J Arthroplasty 1990;5:35-9.

28. Rosenberg AG, Haas B, Barden R, et al. Salvage of infected total knee arthroplasty. Clin Orthop 1988;226:29-33.

29. Goldman RT, Scuderi GR, Insall JN. 2-stage reimplantation for infected total knee replacement. Clin Orthop 1996;331:118-24.

30. Insall JN. Infection of total knee arthroplasty. Instr Course Lectures 1986;35:319-24

31. Insall JN. Surgical techniques and instrumentation in total knee arthroplasty. In: Insall JN, Windsor RE, Scott WN, Kelly MA, Aglietti $\mathrm{P}$, eds. Surgery of the knee. 2nd ed. New York: Churchill Livingstone, 1993:739-804. 
32. Cohen JC, Hozack WJ, Cuckler JM, Booth RE. Two-stage reimplantation of septic total knee arthroplasty: report of three cases using an antibiotic-PMMA spacer block. J Arthroplasty 1988;3:369-77.

33. Calton TF, Fehring TK, Griffin WL. Bone loss associated with the use of spacer blocks in infected total knee arthroplasty. Clin Orthop 1997;345:148-54.

34. Duncan CP, Beauchamp C. A temporary antibiotic-loaded joint replacement system for management of complex infections involving the hip. Orthop Clin North Am 1993;24:751-9.

35. Duncan CP, Masri BA. Editorial. Antibiotic depots. J Bone Joint Surg [Br] 1993;75-B:349-50.

36. Duncan CP, Beauchamp CP, Masri B, et al. The antibiotic loaded joint replacement system: a novel approach to the management of the infected knee replacement. J Bone Joint Surg [Br] 1992;74-B:Suppl III, 296.

37. Windsor RE, Insall JN, Urs WK, Miller DV, Brause BD. Two-stage reimplantation for the salvage of total knee arthroplasty complicated by infection: further follow-up and refinement of indications. $J$ Bone Joint Surg [Am] 1990;72-A:272-8.
38. Cadambi A, Jones RE, Maale GE. A protocol for staged revision of infected total hip and knee arthroplasties: the use of antibiotic-cementimplant composites. Int Orthop 1995;3:133-45.

39. Hofmann AA, Kane KR, Tkach TK, Plaster RL, Camargo MP. Treatment of infected total knee arthroplasty using an articulating spacer. Clin Orthop 1995;321:45-54.

40. McPherson EJ, Lewonowski K, Dorr LD. Use of an articulated PMMA spacer in the infected total knee arthroplasty. J Arthroplasty 1995;10:87-9.

41. Scott IR, Stockley I, Getty CJM. Exchange arthroplasty for infected knee replacements: a new method. J Bone Joint Surg $[\mathrm{Br}]$ 1993;74-B:28-31.

42. Lautenschlager EP, Jacobs JJ, Marshall GW, Meyer PR Jr. Mechanical properties of bone cements containing large doses of antibiotic powders. J Biomed Mater Res 1976;10:929-38.

43. Lautenschlager EP, Marshall GW, Marks KE, Schwartz J, Nelson CL. Mechanical strength of acrylic bone cements impregnated with antibiotics. J Biomed Mater Res 1976;10:837-45.

44. Hebert CK, Williams RE, Levy RS, Barrack RL. Cost of treating an infected total knee replacement. Clin Orthop 1996;331:140-5. 